\title{
Epigenomic diversity of colorectal cancer indicated by LINE-1 methylation in a database of 869 tumors
}

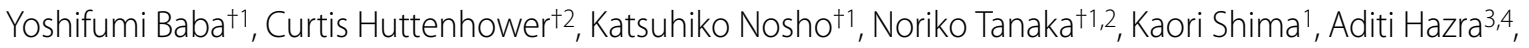 \\ Eva S Schernhammer3,4,5, David J Hunter3,4, Edward L Giovannucci3,4,6, Charles S Fuchs 1,4 and Shuji Ogino*1,7
}

\begin{abstract}
Background: Genome-wide DNA hypomethylation plays a role in genomic instability and carcinogenesis. LINE-1 (L1 retrotransposon) constitutes a substantial portion of the human genome, and LINE-1 methylation correlates with global DNA methylation status. LINE-1 hypomethylation in colon cancer has been strongly associated with poor prognosis. However, whether LINE-1 hypomethylators constitute a distinct cancer subtype remains uncertain. Recent evidence for concordant LINE-1 hypomethylation within synchronous colorectal cancer pairs suggests the presence of a non-stochastic mechanism influencing tumor LINE-1 methylation level. Thus, it is of particular interest to examine whether its wide variation can be attributed to clinical, pathologic or molecular features.
\end{abstract}

Design: Utilizing a database of 869 colorectal cancers in two prospective cohort studies, we constructed multivariate linear and logistic regression models for LINE-1 methylation (quantified by Pyrosequencing). Variables included age, sex, body mass index, family history of colorectal cancer, smoking status, tumor location, stage, grade, mucinous component, signet ring cells, tumor infiltrating lymphocytes, CPG island methylator phenotype (CIMP), microsatellite instability, expression of TP53 (p53), CDKN1A (p21), CTNNB1 ( $\beta$-catenin), PTGS2 (cyclooxygenase-2), and FASN, and mutations in KRAS, BRAF, and PIK3CA.

Results: Tumoral LINE-1 methylation ranged from 23.1 to 90.3 of 0-100 scale (mean 61.4; median 62.3; standard deviation 9.6), and distributed approximately normally except for extreme hypomethylators [LINE-1 methylation < 40; $N=22$ (2.5\%), which were far more than what could be expected by normal distribution]. LINE-1 extreme hypomethylators were significantly associated with younger patients $(p=0.0058)$. Residual plot by multivariate linear regression showed that LINE-1 extreme hypomethylators clustered as one distinct group, separate from the main tumor group. The multivariate linear regression model could explain $8.4 \%$ of the total variability of LINE-1 methylation $(\mathrm{R}$-square $=0.084)$. Multivariate logistic regression models for binary LINE-1 hypomethylation outcomes (cutoffs of 40, 50 and 60) showed at most fair predictive ability (area under receiver operator characteristics curve $<0.63$ ).

Conclusions: LINE-1 extreme hypomethylators appear to constitute a previously-unrecognized, distinct subtype of colorectal cancers, which needs to be confirmed by additional studies. Our tumor LINE-1 methylation data indicate enormous epigenomic diversity of individual colorectal cancers.

\section{Introduction}

DNA methylation is a major epigenetic mechanism in Xchromosome inactivation, imprinting and repression of transposable elements and endogenous retroviral sequences [1]. Global DNA hypomethylation appears to play an important role in genomic instability [2,3], lead-

\footnotetext{
*Correspondence: shuji_ogino@dfci.harvard.edu

1 Department of Medical Oncology, Dana-Farber Cancer Institute and Harvard Medical School, Boston, MA, USA

+ Contributed equally

Full list of author information is available at the end of the article
}

ing to cancer development [4-8]. Since LINE-1 or L1 retrotransposon constitutes a substantial portion (approximately 17\%) of the human genome [9], the methylation status of LINE-1 reflects the global DNA methylation level. Prior studies have shown that tumor LINE-1 methylation correlates with cellular 5-methylcytocine level in cancer tissues [10-12].

In addition to the role as a surrogate marker for global DNA methylation, LINE-1 methylation status by itself likely has biological effects, since retrotransposons such 
as LINE-1 elements can provide alternative promoters [13], and contribute to non-coding RNA expression that regulates functions of a number of genes $[14,15]$. Moreover, retrotransposons activated by DNA hypomethylation may transpose themselves throughout the genome, leading to gene disruptions [16] and chromosomal instability $[4,17]$. LINE-1 methylation has been shown to be highly variable among colon cancers $[18,19]$, and LINE-1 hypomethylation is strongly associated with poor prognosis in colon cancer [20]. However, whether LINE-1 hypomethylators constitute a distinct tumor subtype remains uncertain. Our recent study has shown a significant correlation of LINE-1 methylation levels within synchronous colorectal cancer pairs (i.e., two or more primary tumors in one patient), which suggests the presence of genetic and/or environmental factors influencing LINE-1 methylation levels that are unlikely the result of a purely stochastic phenomenon [21]. Therefore, there are two distinct phenomena - a wide variation of LINE-1 methylation in colorectal cancers and a significant concordance of LINE-1 methylation within synchronous colorectal cancer pairs - raising the intriguing question of whether this wide variation of tumoral LINE-1 methylation can be explained by various clinical, pathologic or molecular variables.

To address this question, we conducted this study with a large database $(\mathrm{N}=869)$ of colorectal cancers identified in two prospective cohort studies and multivariate linear and logistic regression models for LINE-1 methylation level using clinical, pathologic and molecular variables. We have found that the variability in LINE-1 methylation levels remains even after accounting for clinical, pathologic and molecular variables, which indicates epigenomic diversity of colorectal cancers. We have also found that LINE-1 extreme hypomethylators might constitute a previously-unrecognized, distinct cancer subtype, which may have substantial clinical implications with its young age of onset and aggressive behavior [20].

\section{Materials and methods \\ Study group}

We utilized the databases of two large prospective cohort studies, the Nurses' Health Study $(\mathrm{N}=121,700$ women followed since 1976) [22], and the Health Professional Follow-up Study ( $\mathrm{N}=51,529$ men followed since 1986) [22]. Data on height, weight, smoking status, and family history of colorectal cancer in any first-degree relative were obtained by biennial questionnaire. A subset of the cohort participants developed colorectal cancers during prospective follow-up. Previous studies on these cohort studies have described baseline characteristics of participants and incident colorectal cancer cases, and confirmed that our colorectal cancers were well representative as a population-based sample [22]. Data on tumor location and stage were obtained through medical record review. We collected paraffin-embedded tissue blocks from hospitals where patients had undergone resections of colorectal cancers. Based on availability of adequate tissue specimens and results, a total of 869 colorectal cancers were included (Table 1). Among our cohort studies, there was no significant difference in demographic features between cases with tissue available and those without available tissue [22]. This current analysis represents a new study using linear and logistic regression models for LINE-1 methylation on the existing colorectal cancer database (which has been previously characterized for molecular features and clinical outcome [19-24]), leading to the discovery of a possibly novel subtype of colorectal cancers. We comprehensively included many of the previously characterized tumor markers [1924]), which have been linked to colorectal carcinogenesis. In our previous studies which focused on different hypotheses, we examined the relationship between LINE1 methylation and $\mathrm{CpG}$ island methylator phenotype (CIMP) to test the hypothesis whether there is any relationship between global DNA methylation level and CIMP [19]; the relation between LINE-1 methylation and patient survival [20]; the relationship between LINE-1 methylation levels (as one of many molecular markers) within synchronous colorectal cancer pairs [21]; and the relationship between LINE-1 hypomethylation and $18 \mathrm{q}$ loss of heterozygosity (LOH) as a part of analysis on prognostic significance of $18 \mathrm{q} \mathrm{LOH}$ [23]. Informed consent was obtained from all study subjects. Tissue collection and analyses were approved by the Harvard School of Public Health and Brigham and Women's Hospital Institutional Review Boards.

\section{Histopathologic evaluations}

Hematoxylin and eosin (H\&E) stained tissue sections were examined by a pathologist (S.O.) unaware of other data. The tumor grade was categorized as low $(\geq 50 \%$ gland formation) vs. high (<50\% gland formation) [25]. The presence/absence and extent of extracellular mucin and signet ring cells were recorded as percentage of mucinous and signet ring cell components, respectively [25]. Each of Crohn's-like lymphocytic reaction, peritumoral lymphocytic reaction and tumor infiltrating lymphocytes (TIL) was recorded as either absent, mild, moderate or severe [25].

\section{DNA extraction and sodium bisulfite treatment}

The methods for sodium bisulfite treatment of DNA have previously been described [26]. H\&E-stained slides of the tumors were reviewed, and areas of tumor were marked, to exclude pure normal tissue and enrich tumor DNA. Tissue sections (depending on tissue and tumor size, in average, large tumor tissue $10 \mu \mathrm{m} \times 1$ section) from each 
Table 1: LINE-1 methylation level in colorectal cancer.

\begin{tabular}{|c|c|c|c|c|}
\hline Clinical, pathologic or molecular feature & Total N & Mean & Standard deviation & Pvalue^ \\
\hline All cases & 869 & 61.4 & 9.6 & \\
\hline Sex & & & & 0.19 \\
\hline Men & $394(45 \%)$ & 61.0 & 9.0 & \\
\hline Women & $475(55 \%)$ & 61.8 & 10.1 & \\
\hline Age (years) & & & & 0.35 \\
\hline$<60$ & $196(23 \%)$ & 60.5 & 10.5 & \\
\hline $60-69$ & $363(42 \%)$ & 61.7 & 8.7 & \\
\hline$\geq 70$ & $310(36 \%)$ & 61.5 & 9.9 & \\
\hline Body mass index (BMI, $\left.\mathrm{kg} / \mathrm{m}^{2}\right)$ & & & & 0.96 \\
\hline$<30$ & $667(83 \%)$ & 61.3 & 9.5 & \\
\hline$\geq 30$ & $141(17 \%)$ & 61.4 & 9.1 & \\
\hline Family history of colorectal cancer & & & & 0.005 \\
\hline$(-)$ & $657(76 \%)$ & 61.9 & 9.6 & \\
\hline$(+)$ & $212(24 \%)$ & 59.7 & 9.1 & \\
\hline Smoking status & & & & 0.99 \\
\hline Never & $350(41 \%)$ & 61.4 & 10.1 & \\
\hline Past or current & $508(59 \%)$ & 61.3 & 9.2 & \\
\hline Tumor location & & & & 0.024 \\
\hline Proximal colon (cecum to transverse) & $370(44 \%)$ & 61.9 & 9.2 & \\
\hline Distal colon (splenic flexure to sigmoid) & $274(33 \%)$ & 60.1 & 9.7 & \\
\hline Rectum & $192(23 \%)$ & 62.3 & 9.4 & \\
\hline Disease stage & & & & 0.015 \\
\hline I & $196(25 \%)$ & 61.5 & 9.2 & \\
\hline$\|$ & $253(33 \%)$ & 62.5 & 9.2 & \\
\hline III & $226(29 \%)$ & 60.1 & 9.5 & \\
\hline IV & $103(13 \%)$ & 60.0 & 11.0 & \\
\hline Tumor grade & & & & 0.43 \\
\hline Low & 777 (91\%) & 61.3 & 9.4 & \\
\hline High & $79(9.2 \%)$ & 62.3 & 11.2 & \\
\hline Mucinous component & & & & 0.002 \\
\hline $0 \%$ & $554(65 \%)$ & 60.7 & 9.3 & \\
\hline $1-49 \%$ & $188(22 \%)$ & 61.3 & 10.0 & \\
\hline$\geq 50 \%$ & $115(13 \%)$ & 64.1 & 9.3 & \\
\hline Signet ring cell component & & & & 0.009 \\
\hline $0 \%$ & $796(93 \%)$ & 61.0 & 9.4 & \\
\hline $1-49 \%$ & $48(5.6 \%)$ & 63.5 & 10.8 & \\
\hline$\geq 50 \%$ & $14(1.6 \%)$ & 67.6 & 8.5 & \\
\hline Crohn's-like reaction & & & & 0.002 \\
\hline Absent/mild & $684(92 \%)$ & 61.1 & 9.5 & \\
\hline Moderate/severe & $62(8.3 \%)$ & 65.2 & 9.6 & \\
\hline Peritumoral lymphocytic reaction & & & & 0.018 \\
\hline Absent/mild & $744(89 \%)$ & 60.9 & 9.4 & \\
\hline Moderate/severe & $93(11 \%)$ & 63.6 & 10.3 & \\
\hline Tumor infiltrating lymphocytes (TIL) & & & & 0.043 \\
\hline Absent/mild & $740(89 \%)$ & 60.9 & 9.5 & \\
\hline
\end{tabular}


Table 1: LINE-1 methylation level in colorectal cancer. (Continued)

\begin{tabular}{|c|c|c|c|c|}
\hline Moderate/severe & $96(11 \%)$ & 63.2 & 10.2 & \\
\hline MSI status & & & & $<0.0001$ \\
\hline MSI-low/MSS & $728(85 \%)$ & 60.7 & 9.5 & \\
\hline MSI-high & $124(15 \%)$ & 64.7 & 8.9 & \\
\hline CIMP status & & & & $<0.0001$ \\
\hline CIMP-0 & $408(47 \%)$ & 60.2 & 9.8 & \\
\hline CIMP-low & $333(38 \%)$ & 61.3 & 9.3 & \\
\hline CIMP-high & $128(15 \%)$ & 65.1 & 8.3 & \\
\hline CIN status (in MSI-low/MSS cases) & & & & 0.0002 \\
\hline$(-)$ & $142(25 \%)$ & 63.7 & 9.6 & \\
\hline$(+)$ & $436(75 \%)$ & 60.3 & 9.0 & \\
\hline KRAS mutation & & & & 0.90 \\
\hline$(-)$ & $538(63 \%)$ & 61.3 & 9.6 & \\
\hline$(+)$ & $319(37 \%)$ & 61.2 & 9.4 & \\
\hline$B R A F$ mutation & & & & 0.001 \\
\hline$(-)$ & $728(87 \%)$ & 60.8 & 9.3 & \\
\hline$(+)$ & $108(13 \%)$ & 64.2 & 10.2 & \\
\hline PIK3CA mutation & & & & 0.24 \\
\hline$(-)$ & $646(85 \%)$ & 61.1 & 9.7 & \\
\hline$(+)$ & $118(15 \%)$ & 62.2 & 9.3 & \\
\hline TP53 expression & & & & 0.096 \\
\hline$(-)$ & $488(57 \%)$ & 61.8 & 9.8 & \\
\hline$(+)$ & $371(43 \%)$ & 60.7 & 9.3 & \\
\hline CDKN1A (p21) & & & & 0.0002 \\
\hline Lost & $682(81 \%)$ & 60.6 & 9.6 & \\
\hline Expressed & $158(19 \%)$ & 63.7 & 9.0 & \\
\hline CTNNB1 ( $\beta$-catenin) score* & & & & 0.47 \\
\hline $0-2$ (inactive) & $482(64 \%)$ & 61.4 & 9.8 & \\
\hline 3-5 (active) & $273(36 \%)$ & 60.9 & 9.3 & \\
\hline PTGS2 (COX-2) expression & & & & 0.98 \\
\hline$(-)$ & $142(16 \%)$ & 61.3 & 11.2 & \\
\hline$(+)$ & $719(84 \%)$ & 61.3 & 9.2 & \\
\hline FASN expression & & & & 0.16 \\
\hline$(-)$ & $742(88 \%)$ & 61.1 & 9.7 & \\
\hline$(+)$ & 99 (12\%) & 62.4 & 8.7 & \\
\hline
\end{tabular}

$\wedge \mathrm{P}$ value was calculated by t-test assuming unequal variances (for binary variables) or ANOVA (analysis of variance; for 3-category variables). * CTNNB1 score was calculated as previously described [24].

There were cases with missing information in covariates. A $p$ value for significance is adjusted to $p=0.0021$ by Bonferroni correction for multiple hypothesis testing.

CIMP, CpG island methylator phenotype; MSI, microsatellite instability; MSS, microsatellite stable.

case were scraped off slides, suspended in $20 \mu \mathrm{l}$ of the tissue lysate $(100 \mathrm{mmol} / \mathrm{L}$ Tris, $\mathrm{pH} 8,10 \mathrm{mmol} / \mathrm{L}$ ethylenediaminetetraacetic acid, $\mathrm{pH} 8,1 \mathrm{mg} / \mathrm{ml}$ proteinase $\mathrm{K}$, and $0.05 \mathrm{mg} / \mathrm{ml} \mathrm{tRNA}$ ), and incubated at $50^{\circ} \mathrm{C}$ overnight. The tissue lysate was then stored at $-20^{\circ} \mathrm{C}$ until sodium bisulfite treatment was performed. Sodium metabisulfite
$(1.9 \mathrm{~g})$ was dissolved in mixture of $3.2 \mathrm{ml}$ of $0.44 \mathrm{~mol} / \mathrm{L}$ $\mathrm{NaOH}$ at $50^{\circ} \mathrm{C}$. Then, $0.5 \mathrm{ml}$ of $1 \mathrm{~mol} / \mathrm{L}$ hydroquinone was added to the dissolved sodium bisulfite mixture. An $18-\mu \mathrm{l}$ aliquot of the tissue lysate was denatured at $100^{\circ} \mathrm{C}$ for 10 minutes and chilled on ice. Then, $2 \mu \mathrm{l}$ of $3 \mathrm{~mol} / \mathrm{L}$ $\mathrm{NaOH}$ was added and incubated at $42^{\circ} \mathrm{C}$ for 20 minutes. 
The bisulfite solution $(120 \mu \mathrm{l})$ was added (total volume of $140 \mu \mathrm{l}$ ) and incubated at $50^{\circ} \mathrm{C}$ for 15 hours in the dark. The bisulfite-converted DNA was recovered using a Qiagen QIAamp viral RNA mini kit (Qiagen, Valencia, CA) according to the manufacturer's instructions with some modifications. Buffer AVL/carrier RNA (560 $\mu \mathrm{l})$ was added to the $140 \mu \mathrm{l}$ of bisulfite-converted DNA sample and incubated at room temperature for 10 minutes. Ethanol $(560 \mu \mathrm{l})$ was then added, and after extensive mixing, the mixture was loaded onto the provided spin columns in consecutive 630- $\mu$ l aliquots. After each loading, the columns were centrifuged at full speed $(21,000 \times g)$ for 1 minute. Both the filtrate and spin column were saved, and both filtrates were passed through the column a second time in the same manner to increase the yield of recovery. The spin column was then washed with $500 \mu$ of buffer AW1, followed by centrifugation at $21,000 \times g$ for $1 \mathrm{~min}-$ ute. Buffer AW2 $(500 \mu \mathrm{l})$ was then added to the column, and the column was centrifuged at $21,000 \times g$ for 4 minutes to wash the column and eliminate possible buffer AW2 carry over. DNA in the spin column was eluted by the addition of $40 \mu \mathrm{l}$ of buffer AVE, followed by a 1-minute incubation at room temperature and centrifugation at $7600 \times g$ for 1 minute. This elution step was repeated with a second 40- $\mu$ l volume of buffer AVE. Fifty $\mu \mathrm{l}$ of $0.2 \mathrm{~mol} / \mathrm{L}$ $\mathrm{NaOH}$ was added to the $80-\mu \mathrm{l}$ pooled eluate for $15 \mathrm{~min}$ utes at room temperature to desulphonate the sample, and then $10 \mu \mathrm{l}$ of $1 \mathrm{~mol} / \mathrm{L} \mathrm{HCl}$ was added to for neutralization. Buffer AVL/carrier RNA $(560 \mu \mathrm{l})$ was then added to the $140-\mu$ l sample mixture, and the recovery procedure was repeated with a new spin column. The eluted DNA (80- $\mu$ l volume) was then used for Pyrosequencing analysis and MethyLight analysis.

\section{Real-time PCR (MethyLight) for quantitative DNA methylation analysis}

Subsequent real-time PCR (MethyLight) [27] was validated and performed as previously described [26]. We quantified DNA methylation in 8 CIMP-specific promoters [CACNA1G, CDKN2A (p16), CRABP1, IGF2, MLH1, NEUROG1, RUNX3 and SOCS1] [28-30]. CIMP-high was defined as the presence of $\geq 6$ of 8 methylated promoters, CIMP-low as the presence of $1 / 8-5 / 8$ methylated promoters, and CIMP-0 as the absence $(0 / 8)$ of methylated promoters, according to the previously established criteria [30,31].

\section{Pyrosequencing to Measure LINE-1 Methylation}

In order to accurately quantify relatively high LINE-1 methylation levels, we utilized Pyrosequencing technology (Figure 1) [10,19,32]. PCR and subsequent Pyrosequencing for LINE-1 were performed using the PyroMark kit (Qiagen). This assay amplifies a region of LINE-1 element (position 305 to 331 in accession No.
X58075), which includes $4 \mathrm{CpG}$ cites. The PCR condition was 45 cycles of $95^{\circ} \mathrm{C}$ for $20 \mathrm{sec}, 50^{\circ} \mathrm{C}$ for $20 \mathrm{sec}$ and $72^{\circ} \mathrm{C}$ for $20 \mathrm{sec}$, followed by $72^{\circ} \mathrm{C}$ for $5 \mathrm{~min}$. The biotinylated PCR product was purified and made single-stranded to act as a template in a pyrosequencing reaction, using the Pyrosequencing Vacuum Prep Tool (Qiagen). Pyrosequencing reactions were performed in the PSQ HS 96 System (Qiagen). The nucleotide dispensation order was: ACT CAG TGT GTC AGT CAG TTA GTC TG. The non-CpG cytosine in LINE-1 repetitive sequences has been documented to be rarely methylated [33]. Thus, complete conversion of cytosine at a non-CpG site ensured successful bisulfite conversion. The amount of $\mathrm{C}$ relative to the sum of the amounts of $C$ and $T$ at each CpG site was calculated as percentage (i.e., 0 to 100). The average of the relative amounts of $C$ in the $4 \mathrm{CpG}$ sites was used as overall LINE-1 methylation level in a given tumor. LINE-1 methylation level measured by Pyrosequencing is a good indicator of cellular 5-methylcytosine level (i.e., global DNA methylation level) [10,18]. We compared results from cancer cells collected by laser capture microdissection (LCM) with results from cancer tissues dissected manually using HE sections with marking for tumor areas [32]. We showed that DNA hypomethylation could be measured in manually dissected cancer tissue without LCM, and that precision of measurement in manually dissected cancer tissue was superior to cancer cells collected by LCM [32]. In addition, to extensively validate LINE-1 methylation Pyrosequencing assay, we performed bisulfite conversion on seven different DNA specimen aliquots and repeated PCR-Pyrosequencing seven times using 10 macro-dissected colorectal cancers. Bisulfite-to-bisulfite (between-bisulfite treatment) standard deviation ranged from 0.4-2.4 (median, 1.2), and run-to-run (between-PCR Pyrosequencing run) standard deviation ranged from 1.3-4.4 (median, 3.0) [32]. Moreover, intraclass correlation coefficient (ICC) of LINE-1 methylation in cancer tissues was 0.77 , which suggests good reliability in the measurement.

\section{Sequencing of KRAS, BRAF and PIK3CA, and analyses for microsatellite instability (MSI) and chromosomal instability (CIN)}

PCR and Pyrosequencing targeted for KRAS (codons 12 and 13) [34], BRAF (codon 600) [35] and PIK3CA (exons 9 and 20) [36,37] were performed as previously described. MSI analysis was performed, using D2S123, D5S346, D17S250, BAT25, BAT26, BAT40, D18S55, D18S56, D18S67 and D18S487 [38]. MSI-high was defined as the presence of instability in $\geq 30 \%$ of the markers, and MSIlow/microsatellite stability (MSS) as the presence of 0$29 \%$ unstable markers. Loss of heterozygosity (LOH) analysis was performed using microsatellite markers (D2S123, D5S346, D17S250, D18S55, D18S56, D18S67 
A

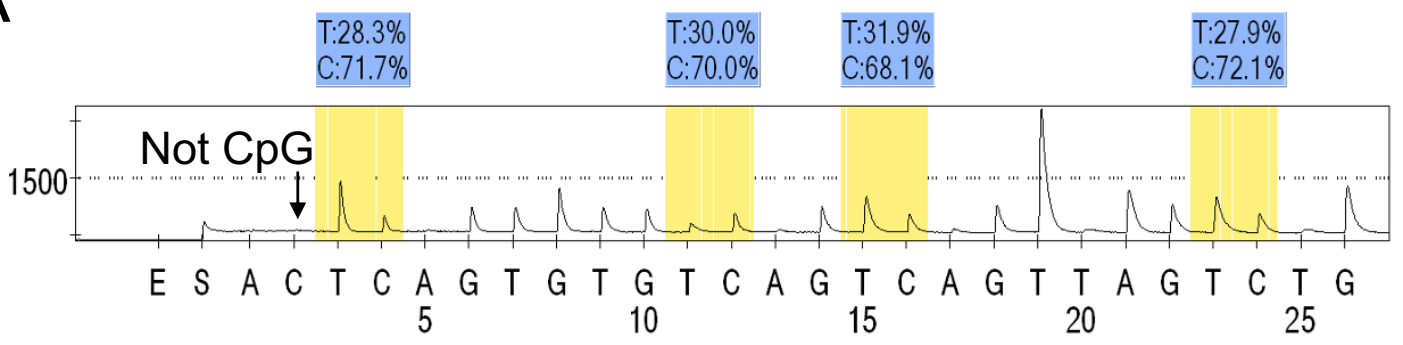

LINE-1 methylation level, 70.5

$\mathrm{B}$

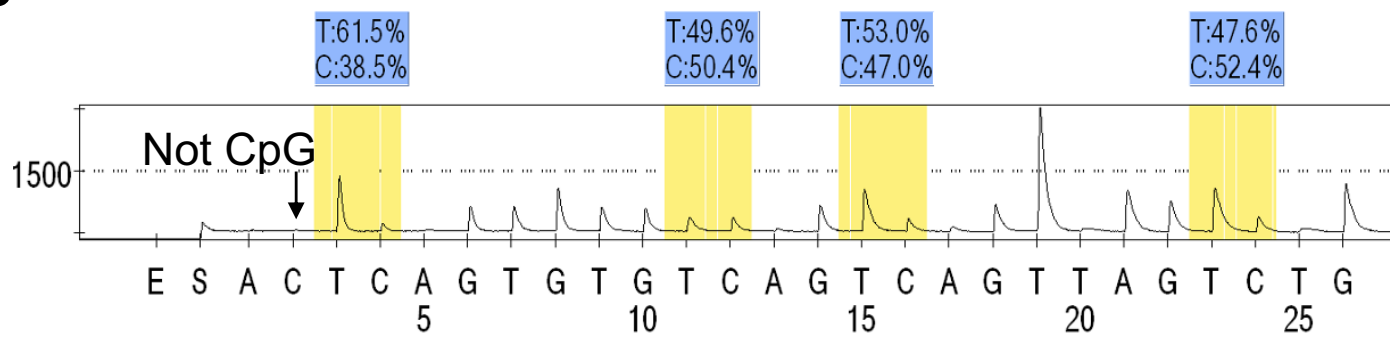

LINE-1 methylation level, 47.1

Figure 1 Pyrosequencing to measure LINE-1 methylation. A. LINE-1 hypermethylated tumor. B. LINE-1 hypomethylated tumor. The \% numbers (in blue shade) are proportions of $\mathrm{C}$ and $\mathrm{T}$ at each $\mathrm{CpG}$ site after bisulfite conversion, and the methylation level of each CpG site is estimated by the proportion of C (\%). An overall LINE-1 methylation level is calculated as the average of the proportions of C (\%) at the 4 CpG sites. The first, third and fourth CpG sites follow mononucleotide T repeats, resulting in higher T peaks (in yellow shade) than the second CpG site, and the proportion of C (\%) has been adjusted accordingly. The arrows indicate no residual $\mathrm{C}$ at the non- $\mathrm{CpG}$ site, ensuring complete bisulfite conversion.

and D18S487). LOH at each locus was defined as $\geq 40 \%$ reduction of one of two allele peaks in tumor DNA relative to normal DNA. CIN positivity was defined as the presence of LOH in any of the chromosomal segments among 2 p, 5 q, 17 q and 18 q, and CIN negativity was defined as the absence of LOH in any of the chromosomal segments with the presence of at least two informative segments $[39,40]$.

\section{Immunohistochemistry for TP53, CDKN1A, CTNNB1, PTGS2 and FASN}

Tissue microarrays (TMA) were constructed as previously described [41]. Methods of immunohistochemistry were previously described for TP53 (p53) [42], CDKN1A (p21) [43,44]; CTNNB1 (ß-catenin) [24]; PTGS2 (cyclooxygenase-2; COX-2) [22,38] and FASN [38,45] (Additional file 1 for the method summary). The CTNNB1 score (i.e., a summation of membrane loss, and cytoplasmic and nuclear localization) used in this current study has been used as a surrogate of CTNNB1 activation caused not only by $A P C$ loss but also by other mechanisms, including $A P C$ mutation, $A P C$ methylation, and CTNNB1 mutation [46]. Appropriate positive and negative controls were included in each run of immunohistochemistry. Each immunohistochemical maker was interpreted by one of the investigators (TP53, CDKN1A, PTGS2 and FASN by S.O.; CTNNB1 by K.N.) unaware of other data. A random selection of 108-179 cases was examined for each marker by a second observer (TP53 and FASN by K.N.; CDKN1A by K.S.; CTNNB1 by S.O.; PTGS2 by R. Dehari, Kanagawa Cancer Center) unaware of other data. The $\kappa$ coefficients between the two observers were 0.65 for CTNNB1 $(\mathrm{N}=142), 0.62$ for CDKN1A $(\mathrm{N}=179), 0.75$ for TP53 $(\mathrm{N}=118), 0.57$ for FASN $(\mathrm{N}=$ 146) and 0.62 for PTGS2 $(\mathrm{N}=108)$ (all $\mathrm{p}<0.0001)$, indicating good to substantial agreement. 


\section{Statistical analysis}

We used the SAS program (Version 9.1, SAS Institute, Cary, NC) for all statistical analyses. All $p$ values were two-sided. Because of multiple hypothesis testing, a p value for significance was adjusted by Bonferroni correction to $\mathrm{p}=0.0021(=0.05 / 24)$. To compare mean LINE-1 methylation levels, we performed the t-test assuming unequal variances or ANOVA for variables with more than 2 categories. Pearson correlation test was used to assess correlations of LINE-1 methylation with raw continuous values of age, body mass index (BMI), percentage of mucinous component and percentage of signet ring cell component. Fisher's exact test was used to assess associations between categorical variables.

We constructed a multivariate linear regression model to assess whether clinical, pathologic and molecular variables could predict LINE-1 methylation level in 869 colorectal cancers. Variables initially included sex, age (continuous), BMI (continuous), smoking status (continuous pack-years), family history of colorectal cancer in any first degree relative (present vs. absent), tumor location (proximal colon vs. distal colon vs. rectum), disease stage (I vs. II vs. III vs. IV vs. unknown), tumor grade (low vs. high), mucinous component (\%, continuous), signet ring cell component (\%, continuous), Crohn's-like reaction (ordinal scale 1-4), peritumoral lymphocytic reaction (ordinal scale 1-4), tumor infiltrating lymphocytes (ordinal scale 1-4), CTNNB1 score (ordinal scale 1-5), CIMP status (high vs. low/0), MSI status (high vs. low/MSS), $B R A F$ (mutant vs. wild-type), KRAS (mutant vs. wildtype), PIK3CA (mutant vs. wild-type), TP53 (positive vs. negative), CDKN1A (expressed vs. lost), PTGS2 (positive vs. negative), and FASN (positive vs. negative). Cases with missing data in a categorical or ordinal variable were included in a majority (or the most common) category; such variables included BMI (7.0\%), tumor location (3.8\%), stage $(10 \%)$, grade $(1.5 \%)$, mucinous component (1.4\%), signet ring cell component (1.3\%), peritumoral lymphocytic reaction (3.7\%), TIL (3.8\%), MSI (2.2\%), KRAS (1.4\%), BRAF (3.8\%), PIK3CA (12\%), TP53 (1.2\%), CDKN1A (3.4\%), CTNNB1 (13\%), PTGS2 (0.9\%) and FASN (3.2\%). We performed multivariate linear regression analysis with a backward stepwise elimination procedure to limit the variables with $\mathrm{p} \leq 0.20$. After the final multivariate linear regression model was constructed, a distribution of residuals (observed LINE-1 methylation level minus predicted LINE-1 methylation level by the regression model) was visually inspected and confirmed that the assumptions of residuals' normality and equal variance across LINE-1 methylation level were generally satisfied. We assessed whether there were any individually influential outliers by residual plots and Cook's D statistics (a summary measure of influence) and found that there were no significant outliers (Cook's D value $<0.035$ for all cases). This indicates that our overall findings were not influenced by any particular outlier subjects.

We assessed potential non-linearity of continuous and ordinal variables (age, BMI, smoking status, disease stage, mucinous component, signet ring cell component, Crohn's-like reaction, peritumoral lymphocytic reaction, tumor infiltrating lymphocytes and CTNNB1 score) by constructing a squared term for each of these variables (excluding data-missing cases) and included these with the original variables in an additional multivariate model. As a result, no squared term showed significant relationship with LINE-1 methylation (all p > 0.20).

In addition, we constructed a multivariate logistic regression model for the binary LINE-1 outcome (cutoff at 40,50 or 60 ) using the same set of covariates as in the final linear regression model. The logistic regression model formula yielded a score for each case based on $\beta$ coefficients and a combination of covariate status. We drew ROC (receiver operator characteristics) curves for the diagnosis of LINE-1 hypomethylation as the binary outcome, using different thresholds of the regression score for test positivity. ROC curves for each cutoff was averaged over 10 folds each using 25\% randomly heldout test data for cross validation. Area under the curve (AUC) value of an averaged ROC curve reflected an ability of a regression model to diagnose binary LINE-1 hypomethylation.

\section{Results}

\section{LINE-1 methylation levels in 869 colorectal cancers}

Utilizing 869 colorectal cancers identified in the two independent prospective cohort studies, we quantified LINE-1 methylation by bisulfite-PCR and Pyrosequencing technology (Figure 1). LINE-1 methylation is a good indicator of cellular methylcytosine level (i.e., global DNA methylation level) [10-12], and the Pyrosequencing assay described here can provide precise data for LINE-1 methylation levels $[10,12,18,32]$. Using the $4 \mathrm{CpG}$ sites in LINE-1, we calculated the average of the percentage numbers (at the $4 \mathrm{CpG}$ sites) of $\mathrm{C}$ (methylated) allele among $\mathrm{C}$ (methylated) and $\mathrm{T}$ (unmethylated) alleles and used this as the LINE-1 methylation level in a given tumor (described as 0 to 100). We previously examined LINE-1 methylation levels in normal colonic mucosa adjacent to colorectal cancers as well as peripheral blood cells from normal individuals, and found that LINE-1 methylation levels in those specimens were high $(>65)$ $[21,32]$. In addition, we previously showed that DNA hypomethylation could be precisely measured in manually dissected cancer tissue, and that precision of LINE-1 methylation measurement in manually dissected cancer tissue was superior to LINE-1 methylation measurement in cancer cells collected by laser capture microdissection (LCM) [32]. Because a manual dissection procedure 
could be easily implemented in this large-scale study and a large amount of DNA could be obtained for better precision, we used manual dissection to obtain DNA from the 869 tumors.

LINE-1 methylation levels in the 869 tumors (Figure 2) widely distributed (ranging from 23.1 to 90.3 of $0-100$ scale; median 62.3; mean 61.4; interquartile range 12.5) and fell into two apparent classes: 22 extreme hypomethylators below a methylation level of 40 , and 847 remaining tumors with normally distributed LINE-1 methylation levels (Shapiro-Wilk $\mathrm{p}>0.20$ for a deviation of normality). We have shown that between-assay variation of LINE-1 methylation levels in repeated measurements is small and coefficient of variation $(\mathrm{CV})$ is $4-5 \%$ [32]; this argues against attributing the large variation in LINE-1 methylation observed between tumors to a laboratory measurement error. In combination with the highly significant association between LINE-1 hypomethylation and patient mortality [20], this indicates that variation in LINE-1 methylation is likely intrinsic to the biology of individual tumors.

\section{LINE-1 methylation and clinical, pathologic and molecular variables}

We examined LINE-1 methylation level in colorectal cancer according to various clinical, pathologic or molecular feature (Table 1). In univariate analysis (with Bonferronicorrected significance level at $\mathrm{p}=0.05 / 24=0.0021)$, LINE-1 methylation was significantly related with mucinous component $(\mathrm{p}=0.002)$, Crohn's-like reaction $(\mathrm{p}=$ 0.002), microsatellite instability (MSI, $\mathrm{p}<0.0001$ ), CpG island methylator phenotype (CIMP, $\mathrm{p}<0.0001$ ), chromosomal instability (CIN) in MSI-low/MSS cases ( $\mathrm{p}=$

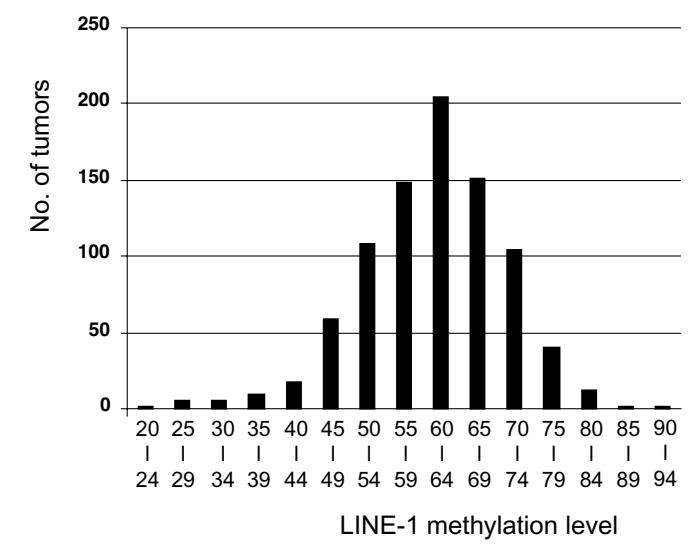

Figure 2 Distribution of LINE-1 methylation levels in 869 colorectal cancers. LINE-1 methylation levels distributed approximately normally, except for the presence of extreme hypomethylators (LINE-1 methylation value $<40$ ), which appear to be separate from the remaining normal distribution.
0.0002), BRAF mutation ( $\mathrm{p}=0.001)$ and CDKN1A (p21) expression $(\mathrm{p}=0.0002)$.

We also examined correlations of LINE-1 methylation with raw values for age, body mass index (BMI), percentage of mucinous component and percentage of signet ring cell component. In all cases, the Pearson correlation coefficient was between 0 and 0.164 (i.e., all $R^{2}<0.027$ ), indicating that none of these variables alone could explain substantial variability of LINE-1 methylation.

\section{Multivariate linear regression analysis for tumoral LINE-1 methylation level}

We constructed a multivariate linear regression model for LINE-1 methylation level as an outcome variable, using clinical, pathologic and other molecular variables. A model that could predict LINE-1 methylation level might be useful, considering the importance of LINE-1 hypomethylation as a highly significant prognostic biomarker in colon cancer [20]. Variables in the multivariate linear regression model initially included sex, age, BMI, family history of colorectal cancer, smoking status, disease stage tumor location, grade, mucinous component, signet ring cells, Crohn's-like reaction, peritumoral lymphocytic reaction, tumor infiltrating lymphocytes (TIL), CIMP, MSI, BRAF mutation, KRAS mutation, PIK3CA mutation, TP53 expression, CDKN1A expression, CTNNB1 score, PTGS2 expression, and FASN expression. We excluded CIN status from our list of covariates because global DNA hypomethylation might be a cause of CIN. Thus, in a linear regression model to predict LINE-1 methylation level (as an outcome variable), a putative consequential variable (such as CIN) should not be put as a predictor variable. After a backward stepwise elimination to avoid overfitting, the variables listed in Table 2 remained in the final model. Importantly, the Rsquare of the final multivariate model was only 0.084 , indicating that $92 \%$ of the LINE-1 methylation variability still remained.

To validate the multivariate linear regression model, we examined the residuals (i.e., observed LINE-1 methylation level minus predicted LINE-1 methylation level by the regression model) (Figure 3). Across all predicted LINE-1 methylation levels, the distribution of residuals was approximately normal and homoscedastic. These results suggested that the multivariate linear regression model was in general appropriately constructed. Of note, there was a cluster of tumors which were separate from the normal and homoscedastic distribution around the 0 residual line. These tumors greatly overlapped with LINE-1 extreme hypomethylators (LINE-1 methylation level < 40).

All variables included in the final multivariate linear regression model are listed in Table 2 . The adjusted $\beta$ coefficient represented an increase in LINE-1 methyla- 
Table 2: Multivariate linear regression analysis to predict LINE-1 methylation level in 869 colorectal cancers

\begin{tabular}{|c|c|c|c|}
\hline Variables in the final model & $\begin{array}{l}\text { Adjusted } \beta \text { coefficient (change in LINE-1 } \\
\text { methylation level by a given variable) }\end{array}$ & 95\% confidence limits & $P$ value (partial F-test) \\
\hline CIMP status & & & $<0.0001$ \\
\hline CIMP-high (vs. CIMP-0) & 4.79 & $2.69,6.89$ & $<0.0001$ ( $\mathrm{T}$ test $)$ \\
\hline CIMP-low (vs. CIMP-0) & 1.17 & $-0.18,2.52$ & 0.090 (T test) \\
\hline $\begin{array}{l}\text { Signet ring cell component (for } 10 \% \\
\text { increase) }\end{array}$ & 1.15 & $0.53,1.77$ & 0.0003 \\
\hline Rectal location (vs. colon) & 2.22 & $0.68,3.75$ & 0.0046 \\
\hline $\begin{array}{l}\text { Family history of colorectal cancer (present } \\
\text { vs. absent) }\end{array}$ & -1.92 & $-3.36,-0.48$ & 0.0089 \\
\hline $\begin{array}{l}\text { Disease stage (for one unit increase in } \\
\text { ordinal scale, I-IV) }\end{array}$ & -0.83 & $-1.50,-0.16$ & 0.016 \\
\hline CDKN1A (p21) loss (vs. expression) & -2.06 & $-3.75,-0.37$ & 0.017 \\
\hline $\begin{array}{l}\text { Crohn's-like reaction [for one unit increase in } \\
\text { ordinal scale } 1 \text { (absent)-4 (strong)] }\end{array}$ & 1.26 & $-0.20,2.31$ & 0.020 \\
\hline High tumor grade (vs. low grade) & -2.47 & $-5.00,0.07$ & 0.056 \\
\hline Male (vs. female) & 1.03 & $-0.24,2.29$ & 0.11 \\
\hline $\begin{array}{l}\text { Body mass index (BMl, for an increase of } 5 \\
\mathrm{~kg} / \mathrm{m}^{2} \text { ) }\end{array}$ & 0.50 & $-0.18,1.18$ & 0.15 \\
\hline \multicolumn{4}{|c|}{$\begin{array}{l}\text { The multivariate linear regression model initially included the variables listed in the table, age, smoking, mucinous component, peritumoral } \\
\text { lymphocytic reaction, tumor infiltrating lymphocytes, CTNNB1 score, MSI status, mutations in BRAF, KRAS and PIK3CA, and expression status of } \\
\text { TP53, CDKN1A (p21), PTGS2 (cyclooxygenase-2), and FASN. A backward elimination with a threshold of } p=0.20 \text { was performed to select variables } \\
\text { in the final model. The adjusted } \beta \text { coefficient represents a change (increase or decrease) in LINE- } 1 \text { methylation level by a given variable, assuming } \\
\text { that all other variables remain constant. R-square of the multivariate model was only } 0.084 \text {, indicating that } 92 \% \text { of variability in LINE- } 1 \\
\text { methylation levels remained unexplained by this model. A p value for significance is adjusted to } p=0.0021 \text { by Bonferroni correction for multiple } \\
\text { hypothesis testing. } \\
\text { CIMP, CpG island methylator phenotype; MSI, microsatellite instability. }\end{array}$} \\
\hline
\end{tabular}

tion level by a given variable, assuming that all other variables remained constant. The most significant predictor was CIMP-high [vs. CIMP-0; adjusted $\beta$ coefficient 4.79; $95 \%$ confidence interval $(\mathrm{CI}), 2.69$ to $6.89 ; \mathrm{p}<0.0001$ ], followed by signet ring cells (for $10 \%$ increase; adjusted $\beta$ coefficient 1.15 ; $95 \%$ CI, 0.53 to $1.77 ; \mathrm{p}=0.0003$ ). Based on the conservative significance level at $\mathrm{p}=0.0021$ by Bonferroni correction for multiple hypothesis testing, no other variables showed robustly significant association, although major indicators including family history, tumor location, and stage showed nominal significance (insufficient to contribute significantly to model accuracy; see Figure 4). All other variables were not significantly associated with LINE-1 methylation.

To eliminate potential confounding effect of HNPCC (hereditary nonpolyposis colorectal cancer), we identified 19 possible or suspected HNPCC cases [i.e., MSI-high CIMP-low/0 tumors (none of which turned out to be $B R A F$-mutated) with any of the followings: (1) positive family history of colorectal cancer in at least one firstdegree relative; (2) loss of MLH1 without evidence of
MLH1 methylation; (3) loss of PMS2 without evidence of MLH1 loss; (4) loss of MSH2 and/or MSH6]. After we excluded these 19 cases, multivariate linear regression analysis showed very similar results (data not shown).

\section{ROC curves for binary LINE-1 methylation outcome in logistic regression analysis}

We constructed multivariate logistic regression models for binary LINE-1 outcomes using different cutoffs (40, 50 and 60) with the same set of covariates as in the final linear regression model. The logistic regression model formula yielded a score for each case based on $\beta$ coefficients and a combination of covariate status. We drew ROC (receiver operator characteristics) curves for the diagnosis of LINE-1 hypomethylation as a binary outcome, using different thresholds of the regression score for test positivity (Figure 4). Area under the curve (AUC) remained relatively low $(<0.63)$ for LINE-1 hypomethylation at a cutoff of $<40,<50$ or $<60$ LINE- 1 methylation. These results also support our finding that LINE-1 methylation status was not well predicted by these variables. 


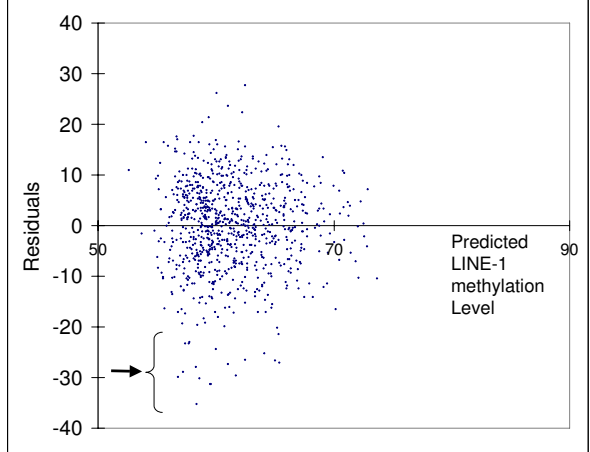

Figure 3 Residuals plot of multivariate linear regression model to predict LINE-1 methylation in $\mathbf{8 6 9}$ colorectal cancers. Each dot represents each case. The $x$ axis represents LINE-1 methylation level predicted by the regression model, and the y axis represents the residuals (observed LINE-1 methylation level minus predicted LINE-1 methylation level by the regression model). A distribution of the residuals is approximately normal across predicted LINE-1 methylation levels, except for the presence of outliers (arrow). The arrow suggests the presence of a distinct group of tumors, separate from the normal and homoscedastic distribution around the 0 residual line.

\section{LINE-1 extreme hypomethylated tumors}

We examined clinical, pathologic and molecular features of tumors with LINE-1 methylation value below 40, because both the overall distribution of LINE-1 methylation levels (Figure 2) and the residuals plot of the linear regression model (Figure 3) indicated the presence of a distinct group of LINE-1 extreme hypomethylators. Notably, there was a relationship between LINE-1 extreme hypomethylation and younger age at diagnosis; $45 \%(10 / 22)$ of cases with LINE-1 methylation $<40$ were less than 60 years old, while only $22 \%(186 / 847)$ of the remaining patients were less than 60 years old ( $\mathrm{p}=$ 0.0058) (Table 3). Overall distribution of age in these LINE-1 < 40 hypomethylators was somewhat bimodal with fewer cases $(14 \%=3 / 22)$ being $60-69$ years old, compared to the remaining patients (with LINE-1 methylation $\geq 40)$ where $43 \%(360 / 847)$ of patients were 60-69 years old. While the total number of LINE- $1<40$ hypomethylators $(\mathrm{N}=22)$ was not enough to achieve statistical significance after Bonferroni correction, this difference in age distribution further supports the presence of a distinct group of LINE-1 extreme hypomethylators. These LINE-1 extreme hypomethylators might arise through a different carcinogenic pathway, resulting in a younger age of onset and more aggressive tumor behavior [20].

\section{Discussion}

In this study, we examined whether clinical, pathologic and molecular variables could potentially explain the wide population variability of LINE-1 methylation in col- orectal cancer. Global DNA hypomethylation has been associated with genomic instability, and implicated in the development of various human cancers [3-7,47-52]. To estimate global DNA methylation level, we measured tumor LINE-1 methylation, which has been correlated well with cellular 5-methylcytosine level (i.e., global DNA methylation level) in cancer tissues [10-12]. This is not surprising because LINE-1 retrotransposon constitutes a substantial portion $(\sim 17 \%)$ of the entire human genome [9]. LINE-1 methylation in colorectal cancer is highly variable $[18,19]$, and is strongly associated with survival among colon cancer patients [20]. Therefore, accurate prediction of tumoral LINE-1 methylation level from clinical and pathological features, if possible, may be clinically useful. Furthermore, recent evidence suggests a non-stochastic component of variable LINE-1 methylation levels in synchronous colorectal cancers (i.e., two or more primary tumors in one individual) [21]. Thus, it is of particular interest to identify clinical, environmental or tumoral factors, if any, which influence LINE-1 methylation in colorectal cancer [53].

Although accumulating evidence has suggested global DNA hypomethylation in human cancers, the mechanisms eliciting this alteration are still unknown. Possible mechanisms include inadequate expression or regulation of DNA methyltransferases, insufficient levels of methyl group donors (i.e., disorder of one-carbon metabolism pathway), aberrant activation of DNA demethylases, and altered expression of chromatin regulators directing DNA methyltransferases [54-56]. The mechanism by which global DNA hypomethylation may confer a poor prognosis (i.e., tumor progression) also remains speculative. Genome-wide DNA hypomethylation has been associated with genomic instability [5], which may confer poor prognosis. Transcriptional dysregulation might be another possible mechanism, and activation of protooncogenes, endogenous retroviruses, or transposable elements might affect tumor aggressiveness. A third possible mechanism involves inflammatory mediators and tumor hypoxia; the latter has been associated with genomic DNA hypomethylation [57]. Activation of hypoxia-inducible factor HIF1A has been associated with poor prognosis in colon cancer [58]. A better understanding of relationship between LINE-1 hypomethylation and clinical, pathologic, or molecular feature may shed lights on these biological mechanisms of LINE-1 hypomethylation in human cancer.

The efficiency and precision of bisulfite conversion is very crucial for quantitative assays based on sodium bisulfite treatment of genomic DNA. As the non-CpG cytosine in LINE-1 repetitive sequences has been documented to be rarely methylated [33], we used the nonCpG cytosine as a built-in control for bisulfite conversion efficiency and confirmed successful bisulfite conversion 


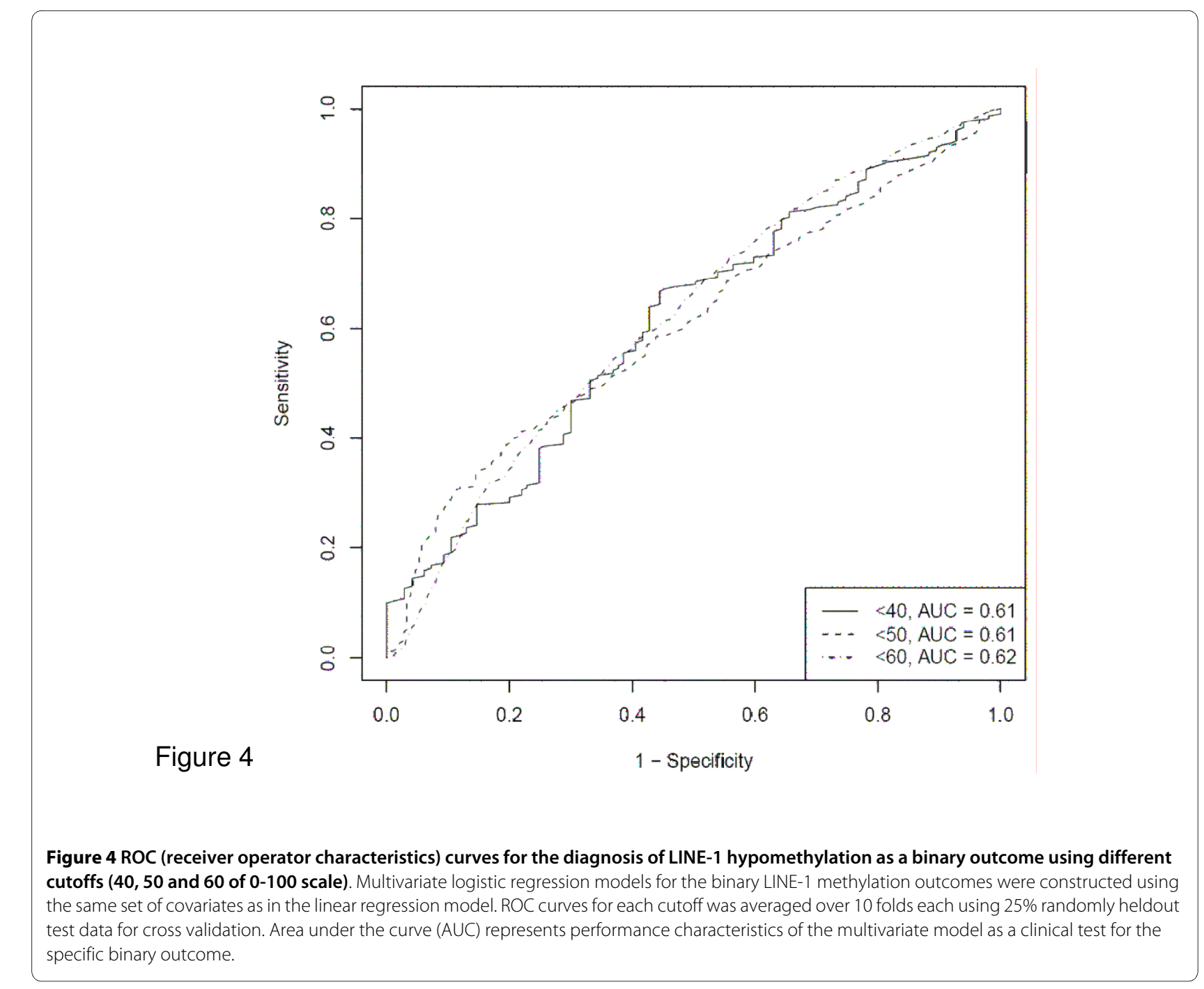

by complete conversion of this cytosine (Figure 1, arrows). In addition, we have previously assessed precision of bisulfite treatment and precision of subsequent Pyrosequencing assay to measure LINE-1 methylation in paraffin-embedded colon cancers [32]. We assessed precision of bisulfite conversion by repeating bisulfite treatment. Basically, we performed bisulfite conversion on seven different DNA specimen aliquots from each of 10 different colorectal cancers. Bisulfite-to-bisulfite (between-bisulfite treatment) standard deviation ranged from 0.4-2.4 (median, 1.2), indicating good precision of bisulfite conversion in terms of LINE-1 methylation measurement.

We have discovered the relationship between LINE-1 extreme hypomethylation $(<40)$ and younger age of onset (< 60 year old). The LINE-1 extreme hypomethylators appear to be separate from the normal distribution of LINE-1 methylation observed in the remaining majority of colorectal cancers. This group of colorectal cancers has not been described previously, because it is necessary to analyze a large number of molecularly and clinicallyannotated colorectal cancers with precise LINE-1 methylation data. The relationship of LINE-1 extreme hypomethylation with earlier age of onset and poor prognosis [20] support the presence of a distinct subtype of colorectal cancers with a unique pathogenic mechanism. Nonetheless, additional studies are necessary to confirm our findings. We are currently investigating whether this class of LINE-1 extreme hypomethylators may indeed be driven by different underlying molecular mechanisms than those inducing the normal distribution of LINE-1 methylation seen in the majority of colorectal cancers.

We have also found that the linear regression model explains only $8.4 \%$ of variability of LINE-1 methylation, and the $92 \%$ of the variability still remained unexplained. In addition, we have shown that multivariate logistic regression models do not significantly predict binary LINE-1 methylation outcomes. Our results imply that 
Table 3: LINE-1 extreme hypomethylators ( $<40)$ compared to colorectal cancers with LINE-1 methylation level $\geq 40$.

\begin{tabular}{|c|c|c|c|c|}
\hline \multirow[t]{2}{*}{ Clinical, pathologic or molecular feature } & \multirow[t]{2}{*}{ Total N } & \multicolumn{2}{|c|}{ LINE-1 methylation level } & \multirow[t]{2}{*}{ P value^ } \\
\hline & & $\geq 40$ & $<40$ & \\
\hline All cases & 869 & 847 & 22 & \\
\hline Sex & & & & 1.00 \\
\hline Men & $394(45 \%)$ & $384(45 \%)$ & $10(45 \%)$ & \\
\hline Women & 475 (55\%) & $463(55 \%)$ & $12(55 \%)$ & \\
\hline Age (years) & & & & 0.0058 \\
\hline$<60$ & $196(23 \%)$ & $186(22 \%)$ & $10(45 \%)$ & \\
\hline $60-69$ & $363(42 \%)$ & $360(43 \%)$ & $3(14 \%)$ & \\
\hline$\geq 70$ & $310(36 \%)$ & $301(36 \%)$ & $9(41 \%)$ & \\
\hline Body mass index (BMI, kg/m²) & & & & 1.00 \\
\hline$<30$ & $667(83 \%)$ & $649(82 \%)$ & $18(86 \%)$ & \\
\hline$\geq 30$ & $141(17 \%)$ & $138(18 \%)$ & $3(14 \%)$ & \\
\hline Family history of colorectal cancer & & & & 0.80 \\
\hline$(-)$ & $657(76 \%)$ & $641(76 \%)$ & $16(73 \%)$ & \\
\hline$(+)$ & $212(24 \%)$ & $206(24 \%)$ & $6(27 \%)$ & \\
\hline Smoking status & & & & 0.082 \\
\hline Never & $349(41 \%)$ & $336(40 \%)$ & $13(59 \%)$ & \\
\hline Past or current & $508(59 \%)$ & $499(60 \%)$ & $9(41 \%)$ & \\
\hline Tumor location & & & & 0.094 \\
\hline Proximal colon (cecum to transverse) & $370(44 \%)$ & $365(45 \%)$ & $5(25 \%)$ & \\
\hline Distal colon (splenic flexure to sigmoid) & $274(33 \%)$ & $263(32 \%)$ & $11(55 \%)$ & \\
\hline Rectum & $192(23 \%)$ & $188(23 \%)$ & $4(20 \%)$ & \\
\hline Disease stage & & & & 0.66 \\
\hline 1 & $196(25 \%)$ & $193(25 \%)$ & $3(14 \%)$ & \\
\hline II & $253(33 \%)$ & $246(32 \%)$ & $7(33 \%)$ & \\
\hline III & $226(29 \%)$ & $218(29 \%)$ & $8(38 \%)$ & \\
\hline IV & $103(13 \%)$ & $100(13 \%)$ & $3(14 \%)$ & \\
\hline Tumor grade & & & & 0.45 \\
\hline Low & 777 (91\%) & $758(91 \%)$ & $19(86 \%)$ & \\
\hline High & $79(9.2 \%)$ & $76(9.1 \%)$ & $3(14 \%)$ & \\
\hline Mucinous component & & & & 0.53 \\
\hline $0 \%$ & $554(65 \%)$ & $541(65 \%)$ & $13(59 \%)$ & \\
\hline $1-49 \%$ & $188(22 \%)$ & $181(22 \%)$ & $7(32 \%)$ & \\
\hline$\geq 50 \%$ & $115(13 \%)$ & $113(14 \%)$ & $2(9.1 \%)$ & \\
\hline Signet ring cell component & & & & 1.00 \\
\hline $0 \%$ & 796 (93\%) & 775 (93\%) & $21(95 \%)$ & \\
\hline $1-49 \%$ & $48(5.6 \%)$ & $47(5.6 \%)$ & $1(4.5 \%)$ & \\
\hline$\geq 50 \%$ & $14(1.6 \%)$ & $14(1.7 \%)$ & 0 & \\
\hline Crohn's-like reaction & & & & 1.00 \\
\hline Absent $/$ mild & $584(90 \%)$ & $571(90 \%)$ & $13(93 \%)$ & \\
\hline Moderate/severe & $62(9.6 \%)$ & $61(9.7 \%)$ & $1(7.1 \%)$ & \\
\hline Peritumoral lymphocytic reaction & & & & 0.73 \\
\hline Absent/mild & 744 (89\%) & 725 (89\%) & 19 (86\%) & \\
\hline
\end{tabular}


Table 3: LINE-1 extreme hypomethylators (<40) compared to colorectal cancers with LINE-1 methylation level $\geq 40$. (Continued)

\begin{tabular}{|c|c|c|c|c|}
\hline Moderate/severe & $93(11 \%)$ & $90(11 \%)$ & $3(14 \%)$ & \\
\hline Tumor infiltrating lymphocytes (TIL) & & & & 0.73 \\
\hline Absent $/ \mathrm{mild}$ & $740(89 \%)$ & $721(89 \%)$ & $19(86 \%)$ & \\
\hline Moderate/severe & $96(11 \%)$ & $93(11 \%)$ & $3(14 \%)$ & \\
\hline MSI status & & & & 0.76 \\
\hline MSI-low/MSS & $728(85 \%)$ & $709(85 \%)$ & $19(90 \%)$ & \\
\hline MSI-high & $124(15 \%)$ & $122(15 \%)$ & $2(9.5 \%)$ & \\
\hline CIMP status & & & & 0.14 \\
\hline CIMP-0 & $408(47 \%)$ & $393(46 \%)$ & $15(68 \%)$ & \\
\hline CIMP-low & $333(38 \%)$ & 327 (39\%) & $6(27 \%)$ & \\
\hline CIMP-high & $128(15 \%)$ & $127(15 \%)$ & $1(4.6 \%)$ & \\
\hline KRAS mutation & & & & 0.38 \\
\hline$(-)$ & $538(63 \%)$ & $522(63 \%)$ & $16(73 \%)$ & \\
\hline$(+)$ & $319(37 \%)$ & $313(37 \%)$ & $6(27 \%)$ & \\
\hline$B R A F$ mutation & & & & 1.00 \\
\hline$(-)$ & $728(87 \%)$ & $709(87 \%)$ & $19(90 \%)$ & \\
\hline$(+)$ & $108(13 \%)$ & $106(13 \%)$ & $2(9.5 \%)$ & \\
\hline PIK3CA mutation & & & & 0.76 \\
\hline$(-)$ & $646(85 \%)$ & $627(84 \%)$ & 19 (90\%) & \\
\hline$(+)$ & $118(15 \%)$ & $116(16 \%)$ & $2(9.5 \%)$ & \\
\hline TP53 expression & & & & 0.19 \\
\hline$(-)$ & $488(57 \%)$ & $472(56 \%)$ & $16(73 \%)$ & \\
\hline$(+)$ & $371(43 \%)$ & 365 (44\%) & $6(27 \%)$ & \\
\hline CDKN1A & & & & 0.099 \\
\hline Lost & $682(81 \%)$ & $661(81 \%)$ & 21 (95\%) & \\
\hline Expressed & $158(19 \%)$ & 157 (19\%) & $1(4.6 \%)$ & \\
\hline CTNNB1 score* & & & & 1.00 \\
\hline 0-2 (inactive) & 482 (64\%) & $470(64 \%)$ & $12(63 \%)$ & \\
\hline 3-5 (active) & $273(36 \%)$ & $266(36 \%)$ & $7(37 \%)$ & \\
\hline PTGS2 expression & & & & 0.073 \\
\hline$(-)$ & $142(16 \%)$ & 135 (16\%) & $7(32 \%)$ & \\
\hline$(+)$ & 719 (84\%) & 704 (84\%) & 15 (68\%) & \\
\hline FASN expression & & & & 0.50 \\
\hline$(-)$ & 742 (88\%) & 721 (88\%) & 21 (95\%) & \\
\hline$(+)$ & 99 (12\%) & $98(12 \%)$ & $1(4.6 \%)$ & \\
\hline
\end{tabular}

(\%) indicates the proportion of cases with a specific clinical, pathologic or molecular feature among tumors with LINE-1 methylation level $\geq$ 40 [or tumors with LINE-1 methylation level < 40]. A p value for significance is adjusted to $p=0.0021$ by Bonferroni correction for multiple hypothesis testing.

$\wedge$ p values were based on Fisher's exact test.

* CTNNB1 score was calculated as previously described [24].

CIMP, CpG island methylator phenotype; MSI, microsatellite instability; MSS, microsatellite stable.

LINE-1 methylation in colorectal cancer can vary greatly even after accounting for the clinical, pathologic and molecular features (examined in this study), despite the uniformity within individual patients in cases of synchronous colorectal cancers [21]. Our data could point to sev- eral interesting potential hypotheses for underlying biological mechanisms; First, genomic methylation levels and tumor progression could be co-influenced by a variety of environmental factors (e.g., smoking, alcohol, or dietary pattern) for each patient. Second, a stochastic ele- 
ment in the underlying regulatory network could be improperly downregulated according to genomic DNA methylation status. Third, specific genes responsible for tumor behavior (e.g., tumor progression) might be aberrantly regulated in cases of extreme hypomethylation. We await further studies to elucidate the exact mechanisms of LINE-1 hypomethylation in colorectal cancers.

Examination of epigenetic and genetic aberrations is important in cancer research [59-64]. We utilized a quantitative Pyrosequencing assay for LINE-1 methylation, which is robust and can accurately quantify LINE-1 methylation level $[10,12]$. Pyrosequencing technology can detect subtle differences in average LINE-1 methylation levels among different colon cancer subtypes [e.g., microsatellite instability (MSI)-high vs. microsatellite stable (MSS)] [18,19], emphasizing the importance of the use of an accurate and precise method to measure LINE1 methylation. Our previous survival data indicates that LINE-1 measurement by Pyrosequencing is highly significantly associated with patient outcome [20]. Considering the high reproducibility of LINE-1 Pyrosequencing $[10,12,32]$, the large variation in LINE-1 methylation levels likely reflects true heterogeneity in global methylation levels among individual tumors. Inter-tumoral biological heterogeneity reflecting the LINE-1 methylation variation is also supported by the highly significant association between LINE-1 methylation level and patient survival [20].

Molecular classification of colorectal cancer based on MSI and the CpG island methylator phenotype (CIMP) status is increasingly important, because MSI and CIMP status reflect global genomic and epigenomic aberrations in tumor cells. Both CIMP-high and MSI-high are inversely associated with LINE-1 hypomethylation, suggesting that CIMP/MSI and genomic hypomethylation may represent different pathways to colorectal cancer. In addition, in non-MSI-high tumors, chromosomal instability (CIN) is correlated with LINE-1 hypomethylation, supporting the possible link between genome-wide hypomethylation and CIN. Further studies are necessary to examine the exact mechanism of how genomic hypomethylation, CIMP, MSI and CIN interact in colorectal cancer development and contribute to colorectal cancer progression.

In the multivariate linear and logistic regression models, we included key molecular events that have been well documented in colorectal cancer [65-68]. Those molecular features include CIMP, MSI and TP53, all of which are related with LINE-1 or global DNA hypomethylation [4$7,18,19,49,50]$. In addition, our tumor database has enabled us to include other molecular variables (such as CDKN1A expression, CTNNB1 score, PTGS2 expression, FASN expression, KRAS mutation, BRAF mutation and PIK3CA mutation, all of which have been related with MSI or CIMP), as well as clinical and pathologic variables. Therefore, our multivariate linear and logistic regression analysis was quite comprehensive.

Although the multivariate linear regression model cannot explain a wide variation of tumoral LINE-1 methylation, the model can provide us with useful information on the independent relations of LINE-1 methylation with various clinical, pathologic and molecular features of colorectal cancer. The possible relationship of LINE-1 methylation with signet ring cell component $(p=0.0003)$ and rectal location (vs. colon; $\mathrm{p}=0.0046$ ) are intriguing. The mechanism of this relation remains to be investigated. In contrast, we found no significant difference in LINE-1 methylation between right colon and left colon, which is in agreement with data on LINE-1 methylation in normal colonic mucosa $[52,53]$. The relation between family history of colorectal cancer and LINE-1 hypomethylation ( $\mathrm{p}$ $=0.0089$ ) may imply the presence of genetic component in global DNA hypomethylation. Of note, we have previously reported that certain SNPs in one-carbon metabolism genes are not associated with LINE-1 hypomethylation [69]. Nonetheless, any of associations with $\mathrm{p}>0.0021$ in this current study could be a chance finding due to multiple hypothesis testing. Additional independent studies are necessary to confirm these associations.

\section{Conclusions}

In this study utilizing large database of 869 colorectal cancers, we have shown three main findings; first, LINE-1 extreme hypomethylators skew a distribution of LINE-1 to a non-normal distribution, and constitute a cluster in the residuals plot in multivariate linear regression. Second, LINE-1 extreme hypomethylation is associated with younger age of onset, suggesting the presence of a previously-unrecognized, distinct cancer subtype. Third, LINE-1 methylation level in colorectal cancer varies greatly, even after accounting for various clinicopathologic and other molecular variables. Our results support enormous epigenomic diversity of colorectal cancers in terms of LINE-1 methylation status and a possible subset of mechanistically distinct LINE-1 extreme hypomethylators. These findings may have considerable clinical implications, since LINE-1 hypomethylated colon cancers exhibit aggressive clinical behavior [20].

\section{Additional material}

Additional file 1 The method summary. This supplementary table summarizes the methods to evaluate LINE-1 methylation, KRAS, BRAF and PIK3CA mutation, CIMP, MSI, CIN, and expression for TP53, CDKN1A, CTNNB1, PTGS2, and FASN. 


\section{Abbreviations}

AJCC: American Joint Committee on Cancer; ANOVA: analysis of variance; AUC area under the curve; $\mathrm{Cl}$ : confidence interval; CIMP: CpG island methylator phenotype; CIN: chromosomal instability; ICC: intraclass correlation coefficient; $\mathrm{LOH}$ : loss of heterozygosity; MSI: microsatellite instability; MSS: microsatellite stable; ROC: receiver operator characteristics; SD: standard deviation; TIL: tumor infiltrating lymphocytes.

\section{Competing interests}

The authors declare that they have no competing interests.

\section{Authors' contributions}

SO conceived the study. YB, CH, KN, NT, KS, ELG, CSF, SO collected data. YB, CH, $\mathrm{KN}, \mathrm{NT}, \mathrm{KS}, \mathrm{AH}, \mathrm{ESS}, \mathrm{DJH}, \mathrm{ELG}, \mathrm{CSF}, \mathrm{SO}$ analyzed and interpreted data. SO drafted the manuscript. All authors read, edited and approved the manuscript.

\section{Acknowledgements}

We deeply thank the Nurses' Health Study and Health Professionals Follow-up Study cohort participants who have generously agreed to provide us with biological specimens and information through responses to questionnaires; hospitals and pathology departments throughout the U.S. for providing us with tumor tissue materials; Walter Willett, Susan Hankinson, Meir Stampfer, and many other staff members who implemented and have maintained the cohort studies.

Grant Support: This work was supported by U.S. National Institute of Health [P01 CA87969 (to S. Hankinson), P01 CA55075 (to W. Willett), P50 CA127003 (to C.S.F.), K07 CA122826 (to S.O.)]; the Bennett Family Fund for Targeted Therapies Research; and the Entertainment Industry Foundation National Colorectal Cancer Research Alliance. K.N. was supported by a fellowship grant from the Japan Society for the Promotion of Science. The content is solely the responsibility of the authors and does not necessarily represent the official views of $\mathrm{NCl}$ or $\mathrm{NIH}$. Funding agencies did not have any role in the design of the study; the collection, analysis, or interpretation of the data; the decision to submit the manuscript for publication; or the writing of the manuscript.

\section{Author Details}

1Department of Medical Oncology, Dana-Farber Cancer Institute and Harvard Medical School, Boston, MA, USA, 2Department of Biostatistics, Harvard School of Public Health, Boston, MA, USA, ${ }^{3}$ Department of Epidemiology, Harvard School of Public Health, Boston, MA, USA, ${ }^{4}$ Channing Laboratory, Department of Medicine, Brigham and Women's Hospital and Harvard Medical School, Boston, MA, USA, 5 Ludwig Boltzmann-Institute for Applied Cancer Research, and Applied Cancer Research - Institution for Translational Research, Vienna, Austria, ${ }^{6}$ Department of Nutrition, Harvard School of Public Health, Boston, MA, USA and 'Department of Pathology, Brigham and Women's Hospital and Harvard Medical School, Boston, MA, USA

Received: 8 December 2009 Accepted: 27 May 2010 Published: 27 May 2010

\section{References}

1. Jones PA, Baylin SB: The epigenomics of cancer. Cell 2007, 128(4):683-692.

2. Bestor TH: Transposons reanimated in mice. Cell 2005, 122(3):322-325.

3. Gaudet F, Hodgson JG, Eden A, Jackson-Grusby L, Dausman J, Gray JW, Leonhardt $\mathrm{H}$, Jaenisch $\mathrm{R}$ : Induction of tumors in mice by genomic hypomethylation. Science 2003, 300(5618):489-492.

4. Yamada Y, Jackson-Grusby L, Linhart H, Meissner A, Eden A, Lin H, Jaenisch R: Opposing effects of DNA hypomethylation on intestinal and liver carcinogenesis. Proc Natl Acad Sci USA 2005, 102(38):13580-13585.

5. Rodriguez J, Frigola J, Vendrell E, Risques RA, Fraga MF, Morales C, Moreno V, Esteller M, Capella G, Ribas M, Peinado MA: Chromosomal Instability Correlates with Genome-wide DNA Demethylation in Human Primary Colorectal Cancers. Cancer Res 2006, 66(17):8462-9468.

6. Suzuki K, Suzuki I, Leodolter A, Alonso S, Horiuchi S, Yamashita K, Perucho $\mathrm{M}$ : Global DNA demethylation in gastrointestinal cancer is age dependent and precedes genomic damage. Cancer Cell 2006, 9(3):199-207.

7. Karpf AR, Matsui S: Genetic disruption of cytosine DNA methyltransferase enzymes induces chromosomal instability in human cancer cells. Cancer Res 2005, 65(19):8635-8639.
8. Lim U, Flood A, Choi SW, Albanes D, Cross AJ, Schatzkin A, Sinha R, Katki HA, Cash B, Schoenfeld P, Stolzenberg-Solomon R: Genomic methylation of leukocyte DNA in relation to colorectal adenoma among asymptomatic women. Gastroenterology 2008, 134(1):47-55.

9. Cordaux R, Batzer MA: The impact of retrotransposons on human genome evolution. Nat Rev Genet 2009, 10(10):691-703.

10. Yang AS, Estecio MR, Doshi K, Kondo Y, Tajara EH, Issa JP: A simple method for estimating global DNA methylation using bisulfite PCR of repetitive DNA elements. Nucleic Acids Res 2004, 32(3):e38.

11. Weisenberger DJ, Campan M, Long TI, Kim M, Woods C, Fiala E, Ehrlich M, Laird PW: Analysis of repetitive element DNA methylation by MethyLight. Nucleic Acids Res 2005, 33(21):6823-6836.

12. Yang AS, Doshi KD, Choi SW, Mason JB, Mannari RK, Gharybian V, Luna R, Rashid A, Shen L, Estecio MR, Kantarjian HM, Garcia-Manero G, Issa JP: DNA methylation changes after 5-aza-2'-deoxycytidine therapy in patients with leukemia. Cancer Res 2006, 66(10):5495-5503.

13. Speek M: Antisense promoter of human L1 retrotransposon drives transcription of adjacent cellular genes. Mol Cell Biol 2001, 21(6):1973-1985.

14. Peaston AE, Evsikov AV, Graber JH, de Vries WN, Holbrook AE, Solter D, Knowles BB: Retrotransposons regulate host genes in mouse oocytes and preimplantation embryos. Dev Cell 2004, 7(4):597-606.

15. Faulkner GJ, Kimura Y, Daub CO, Wani S, Plessy C, Irvine KM, Schroder K, Cloonan N, Steptoe AL, Lassmann T, Waki K, Hornig N, Arakawa T, Takahashi H, Kawai J, Forrest AR, Suzuki H, Hayashizaki Y, Hume DA, Orlando V, Grimmond SM, Carninci P: The regulated retrotransposon transcriptome of mammalian cells. Nat Genet 2009, 41(5):563-571.

16. Han JS, Szak ST, Boeke JD: Transcriptional disruption by the L1 retrotransposon and implications for mammalian transcriptomes. Nature 2004, 429(6989):268-274.

17. Howard G, Eiges R, Gaudet F, Jaenisch R, Eden A: Activation and transposition of endogenous retroviral elements in hypomethylation induced tumors in mice. Oncogene 2008, 27(3):404-408.

18. Estecio MR, Gharibyan V, Shen L, Ibrahim AE, Doshi K, He R, Jelinek J, Yang AS, Yan PS, Huang TH, Tajara EH, Issa JP: LINE-1 hypomethylation in cancer is highly variable and inversely correlated with microsatellite instability. PLOS ONE 2007, 2(5):e399.

19. Ogino S, Kawasaki T, Nosho K, Ohnishi M, Suemoto Y, Kirkner GJ, Fuchs CS: LINE-1 hypomethylation is inversely associated with microsatellite instability and CpG methylator phenotype in colorectal cancer. Int J Cancer 2008, 122:2767-2773.

20. Ogino S, Nosho K, Kirkner GJ, Kawasaki T, Chan AT, Schernhammer ES, Giovannucci EL, Fuchs CS: A cohort study of tumoral LINE-1 hypomethylation and prognosis in colon cancer. J Natl Cancer Inst 2008, 100:1734-1738.

21. Nosho K, Kure S, Irahara N, Shima K, Baba Y, Spiegelman D, Meyerhardt JA, Giovannucci EL, Fuchs CS, Ogino S: A prospective cohort study shows unique epigenetic, genetic, and prognostic features of synchronous colorectal cancers. Gastroenterology 2009, 137(5):1609-1620. e1603.

22. Chan AT, Ogino S, Fuchs CS: Aspirin and the Risk of Colorectal Cancer in Relation to the Expression of COX-2. New Engl J Med 2007, 356(21):2131-2142.

23. Ogino S, Nosho K, Irahara N, Shima K, Baba Y, Kirkner GJ, Meyerhardt JA, Fuchs CS: Prognostic significance and molecular associations of $18 \mathrm{q}$ loss of heterozygosity: a cohort study of microsatellite stable colorectal cancers. J Clin Oncol 2009, 26(35):5713-5720.

24. Kawasaki T, Nosho K, Ohnishi M, Suemoto Y, Kirkner GJ, Meyerhardt JA, Fuchs CS, Ogino S: Correlation of beta-catenin localization with cyclooxygenase-2 expression and CpG island methylator phenotype (CIMP) in colorectal cancer. Neoplasia 2007, 9(7):569-577.

25. Ogino S, Odze RD, kawasaki T, Brahmandam M, Kirkner GJ, Laird PW, Loda $\mathrm{M}$, Fuchs CS: Correlation of pathologic features with CpG island methylator phenotype (CIMP) by quantitative DNA methylation analysis in colorectal carcinoma. Am J Surg Patho/ 2006, 30(9):1175-1183.

26. Ogino S, kawasaki T, Brahmandam M, Cantor M, Kirkner GJ, Spiegelman D, Makrigiorgos GM, Weisenberger DJ, Laird PW, Loda M, Fuchs CS: Precision and performance characteristics of bisulfite conversion and real-time PCR (MethyLight) for quantitative DNA methylation analysis. $\mathrm{J} \mathrm{Mol}$ Diagn 2006, 8(2):209-217. 
27. Eads CA, Danenberg KD, Kawakami K, Saltz LB, Blake C, Shibata D, Danenberg PV, Laird PW: MethyLight: a high-throughput assay to measure DNA methylation. Nucleic Acids Res 2000, 28(8):E32.

28. Ogino S, Cantor M, Kawasaki T, Brahmandam M, Kirkner G, Weisenberger DJ, Campan M, Laird PW, Loda M, Fuchs CS: CpG island methylator phenotype (CIMP) of colorectal cancer is best characterised by quantitative DNA methylation analysis and prospective cohort studies. Gut 2006, 55:1000-1006.

29. Weisenberger DJ, Siegmund KD, Campan M, Young J, Long TI, Faasse MA, Kang GH, Widschwendter M, Weener D, Buchanan D, Koh H, Simms L, Barker M, Leggett B, Levine J, Kim M, French AJ, Thibodeau SN, Jass J, Haile R, Laird PW: CpG island methylator phenotype underlies sporadic microsatellite instability and is tightly associated with BRAF mutation in colorectal cancer. Nat Genet 2006, 38(7):787-793.

30. Nosho K, Irahara N, Shima K, Kure S, Kirkner GJ, Schernhammer ES, Hazra A, Hunter DJ, Quackenbush J, Spiegelman D, Giovannucci EL, Fuchs CS, Ogino S: Comprehensive biostatistical analysis of $\mathrm{CpG}$ island methylator phenotype in colorectal cancer using a large populationbased sample. PLOS ONE 2008, 3(11):e3698.

31. Ogino S, Kawasaki T, Kirkner GJ, Kraft P, Loda M, Fuchs CS: Evaluation of markers for $\mathrm{CpG}$ island methylator phenotype (CIMP) in colorectal cancer by a large population-based sample. J Mol Diagn 2007, 9(3):305-314.

32. Irahara N, Nosho K, Baba Y, Shima K, Lindeman NI, Hazra A, Schernhammer ES, Hunter DJ, Fuchs CS, Ogino S: Precision of Pyrosequencing assay to measure LINE-1 methylation in colon cancer, normal colonic mucosa and peripheral blood cells. J Mol Diagn 2010, 12(2):177-183.

33. Burden AF, Manley NC, Clark AD, Gartler SM, Laird CD, Hansen RS: Hemimethylation and non-CpG methylation levels in a promoter region of human LINE-1 (L1) repeated elements. J Biol Chem 2005, 280(15):14413-14419.

34. Ogino S, Kawasaki T, Brahmandam M, Yan L, Cantor M, Namgyal C, MinoKenudson M, Lauwers GY, Loda M, Fuchs CS: Sensitive sequencing method for KRAS mutation detection by Pyrosequencing. $J$ Mol Diagn 2005, 7(3):413-421.

35. Ogino S, Kawasaki T, Kirkner GJ, Loda M, Fuchs CS: CpG island methylator phenotype-low (CIMP-low) in colorectal cancer: possible associations with male sex and KRAS mutations. J Mol Diagn 2006, 8:582-588.

36. Nosho K, Kawasaki T, Ohnishi M, Suemoto Y, Kirkner GJ, Zepf D, Yan L, Longtine JA, Fuchs CS, Ogino S: PIK3CA mutation in colorectal cancer: relationship with genetic and epigenetic alterations. Neoplasia 2008, 10(6):534-541

37. Ogino S, Nosho K, Kirkner GJ, Shima K, Irahara N, Kure S, Chan AT, Engelman JA, Kraft P, Cantley LC, Giovannucci EL, Fuchs CS: PIK3CA mutation is associated with poor prognosis among patients with curatively resected colon cancer. J Clin Oncol 2009, 27:1477-1484.

38. Ogino S, Brahmandam M, Cantor M, Namgyal C, Kawasaki T, Kirkner G, Meyerhardt JA, Loda M, Fuchs CS: Distinct molecular features of colorectal carcinoma with signet ring cell component and colorectal carcinoma with mucinous component. Mod Pathol 2006, 19(1):59-68.

39. Baba Y, Nosho K, Shima K, Irahara N, Kure S, Toyoda S, Kirkner GJ, Goel A, Fuchs CS, Ogino S: Aurora-A expression is independently associated with chromosomal instability in colorectal cancer. Neoplasia 2009, 11(5):418-425

40. Nosho K, Shima K, Kure S, Irahara N, Baba Y, Chen L, Kirkner GJ, Fuchs CS, Ogino S: JC virus T-antigen in colorectal cancer is associated with p53 expression and chromosomal instability, independent of $\mathrm{CpG}$ island methylator phenotype. Neoplasia 2009, 11(1):87-95

41. Ogino S, Brahmandam M, Kawasaki T, Kirkner GJ, Loda M, Fuchs CS: Combined analysis of COX-2 and p53 expressions reveals synergistic inverse correlations with microsatellite instability and $\mathrm{CpG}$ island methylator phenotype in colorectal cancer. Neoplasia 2006, 8(6):458-464.

42. Ogino S, kawasaki T, Kirkner GJ, Yamaji T, Loda M, Fuchs CS: Loss of nuclear p27 (CDKN1B/KIP1) in colorectal cancer is correlated with microsatellite instability and CIMP. Mod Pathol 2007, 20:15-22.

43. Ogino S, Meyerhardt JA, Cantor M, Brahmandam M, Clark JW, Namgyal C, Kawasaki T, Kinsella K, Michelini AL, Enzinger PC, Kulke MH, Ryan DP, Loda $M$, Fuchs CS: Molecular alterations in tumors and response to combination chemotherapy with gefitinib for advanced colorectal cancer. Clin Cancer Res 2005, 11(18):6650-6656.
44. Ogino S, kawasaki T, Kirkner GJ, Ogawa A, Dorfman I, Loda M, Fuchs CS: Down-regulation of p21 (CDKN1A/CIP1) is inversely associated with microsatellite instability and CpG island methylator phenotype (CIMP) in colorectal cancer. J Pathol 2006, 210(2):147-154

45. Ogino S, Nosho K, Meyerhardt JA, Kirkner GJ, Chan AT, Kawasaki T, Giovannucci EL, Loda M, Fuchs CS: Cohort study of fatty acid synthase expression and patient survival in colon cancer. J Clin Oncol 2008, 26(35):5713-5720.

46. Jass JR, Biden KG, Cummings MC, Simms LA, Walsh M, Schoch E, Meltzer SJ, Wright C, Searle J, Young J, Leggett BA: Characterisation of a subtype of colorectal cancer combining features of the suppressor and mild mutator pathways. J Clin Pathol 1999, 52(6):455-460.

47. Holm TM, Jackson-Grusby L, Brambrink T, Yamada Y, Rideout WM, Jaenisch R: Global loss of imprinting leads to widespread tumorigenesis in adult mice. Cancer Cell 2005, 8(4):275-285.

48. Chalitchagorn K, Shuangshoti S, Hourpai N, Kongruttanachok N, Tangkijvanich P, Thong-ngam D, Voravud N, Sriuranpong V, Mutirangura A: Distinctive pattern of LINE-1 methylation level in normal tissues and the association with carcinogenesis. Oncogene 2004, 23(54):8841-8846.

49. Matsuzaki K, Deng G, Tanaka H, Kakar S, Miura S, Kim YS: The relationship between global methylation level, loss of heterozygosity, and microsatellite instability in sporadic colorectal cancer. Clin Cancer Res 2005, 11(24):8564-8569.

50. Ji W, Hernandez R, Zhang XY, Qu GZ, Frady A, Varela M, Ehrlich M: DNA demethylation and pericentromeric rearrangements of chromosome 1. Mutat Res 1997, 379(1):33-41

51. Derks S, Postma C, Carvalho B, Bosch SM van den, Moerkerk PT, Herman $J G$, Weijenberg MP, de Bruine AP, Meijer GA, van Engeland M: Integrated analysis of chromosomal, microsatellite and epigenetic instability in colorectal cancer identifies specific associations between promoter methylation of pivotal tumour suppressor and DNA repair genes and specific chromosomal alterations. Carcinogenesis 2008, 29(2):434-439.

52. lacopetta B, Grieu F, Phillips M, Ruszkiewicz A, Moore J, Minamoto T, Kawakami K: Methylation levels of LINE-1 repeats and CpG island loci are inversely related in normal colonic mucosa. Cancer Sci 2007, 98(9):1454-1460.

53. Figueiredo JC, Grau MV, Wallace K, Levine AJ, Shen L, Hamdan R, Chen X, Bresalier RS, McKeown-Eyssen G, Haile RW, Baron JA, Issa JP: Global DNA hypomethylation (LINE-1) in the normal colon and lifestyle characteristics and dietary and genetic factors. Cancer Epidemiol Biomarkers Prev 2009, 18(4):1041-1049.

54. Goodier JL, Kazazian HH Jr: Retrotransposons revisited: the restraint and rehabilitation of parasites. Cell 2008, 135(1):23-35

55. Schulz WA: L1 retrotransposons in human cancers. J Biomed Biotechnol 2006, 2006(1):83672.

56. Pogribny IP, Beland FA: DNA hypomethylation in the origin and pathogenesis of human diseases. Cell Mol Life Sci 2009, 66(14):2249-2261

57. Shahrzad S, Bertrand K, Minhas K, Coomber BL: Induction of DNA hypomethylation by tumor hypoxia. Epigenetics 2007, 2(2):119-125.

58. Baba Y, Nosho K, Shima K, Irahara N, Chan AT, Meyerhardt JA, Chung DC, Giovannucci EL, Fuchs CS, Ogino S: HIF1A overexpression is associated with poor prognosis in a cohort of 731 colorectal cancers. Am J Pathol 2010, 176(5):2292-2301

59. Nakamura Y, Yogosawa S, Izutani Y, Watanabe H, Otsuji E, Sakai T: A combination of indol-3-carbinol and genistein synergistically induces apoptosis in human colon cancer HT-29 cells by inhibiting Akt phosphorylation and progression of autophagy. Mol Cancer 2009, 8:100.

60. Prokunina-Olsson L, Hall JL: No effect of cancer-associated SNP rs6983267 in the 8 q24 region on co-expression of MYC and TCF7L2 in normal colon tissue. Mol Cancer 2009, 8:96.

61. Koslowski M, Tureci O, Huber C, Sahin U: Selective activation of tumor growth-promoting $\mathrm{Ca} 2+$ channel MS4A12 in colon cancer by caudal type homeobox transcription factor CDX2. Mol Cancer 2009, 8:77.

62. Denkert C, Budczies J, Weichert W, Wohlgemuth G, Scholz M, Kind T, Niesporek S, Noske A, Buckendahl A, Dietel M, Fiehn O: Metabolite profiling of human colon carcinoma--deregulation of TCA cycle and amino acid turnover. Mol Cancer 2008, 7:72.

63. Ahlquist T, Lind GE, Costa VL, Meling GI, Vatn M, Hoff GS, Rognum TO, Skotheim RI, Thiis-Evensen E, Lothe RA: Gene methylation profiles of 
normal mucosa, and benign and malignant colorectal tumors identify early onset markers. Mol Cancer 2008, 7:94.

64. Brim H, Mokarram P, Naghibalhossaini F, Saberi-Firoozi M, Al-Mandhari M, Al-Mawaly K, Al-Mjeni R, Al-Sayegh A, Raeburn S, Lee E, Giardiello F, Smoot DT, Vilkin A, Boland CR, Goel A, Hafezi M, Nouraie M, Ashktorab H: Impact of BRAF, MLH1 on the incidence of microsatellite instability high colorectal cancer in populations based study. Mol Cancer 2008, 7:68

65. Teodoridis JM, Hardie C, Brown R: CpG island methylator phenotype (CIMP) in cancer: Causes and implications. Cancer Lett 2008, 268(2):177-186.

66. Wong JJ, Hawkins NJ, Ward RL: Colorectal cancer: a model for epigenetic tumorigenesis. Gut 2007, 56(1):140-148.

67. Walther A, Johnstone E, Swanton C, Midgley R, Tomlinson I, Kerr D: Genetic prognostic and predictive markers in colorectal cancer. Nat Rev Cancer 2009, 9(7):489-499.

68. Grady WM, Carethers JM: Genomic and epigenetic instability in colorectal cancer pathogenesis. Gastroenterology 2008, 135(4):1079-1099

69. Hazra A, Fuchs CS, Kawasaki T, Kirkner GJ, Hunter DJ, Ogino S: Germline polymorphisms in the one-carbon metabolism pathway and DNA methylation in colorectal cancer. Cancer Causes Control 2010:331-345.

doi: $10.1186 / 1476-4598-9-125$

Cite this article as: Baba et al., Epigenomic diversity of colorectal cancer indicated by LINE-1 methylation in a database of 869 tumors Molecular Cancer 2010, 9:125

Submit your next manuscript to BioMed Centra and take full advantage of:

- Convenient online submission

- Thorough peer review

- No space constraints or color figure charges

- Immediate publication on acceptance

- Inclusion in PubMed, CAS, Scopus and Google Scholar

- Research which is freely available for redistribution 